\title{
How do the Dutch Choose their Hospitals? Results from a Survey among 311 Patients
}

\author{
Suzanne Bartelink ${ }^{1}$ and Christiaan J. Lako ${ }^{*}$ \\ ${ }^{1}$ Department of public Administration Radboud University Nijmegen, P.o.Box 9108,6500 Hk Nijmegen, The Netherlands \\ ${ }^{2}$ Department of public Administration, Radboud University Nijmegen, P.o.Box 9108,6500 Hk Nijmegen, The Netherlands
}

\begin{abstract}
Objective: Although it is widely assumed that in the Netherlands patients use public information from websites in their hospital choice, empirical data on the actual use of such information is scarce. Our aim is to describe the process of hospital choice and to study what factors, including social media, are related to hospital choice.
\end{abstract}

Methods: In June 2011, a sample was drawn from patients who were seeking out-patient care from hospital-based clinics in the CWZ hospital in Nijmegen, the Netherlands. These patients were asked to fill in a short, self-administered questionnaire about hospital choice. A total of 419 patients visiting the hospital was included. The response rate was $74 \%(n=311)$.

Results: Only $1.3 \%$ of the patients reported having used public information in their hospital choice. Most patients $(85.2 \%)$ stated that they had been referred by their GP. Information from the GP, age, previous experience with the hospital and belonging to a specific patient group are much more important in the hospital choice process than written information and social media.

Conclusions: So far, the assumption that patients use public information from websites or social media in their hospital choice appears to be unfounded.

\section{Introduction}

Dutch healthcare has been reformed in recent years. On January 1,2006 , the three-tiered mix of public and private health insurance in the Netherlands was replaced by a new, free market health insurance system. The 2006 Health Insurance Act is based on the demand-driven healthcare model. Insurance companies are no longer required to contract with all providers, instead they are encouraged to choose on the basis of negotiated arrangements with the providers which, to their mind, are cheapest and guarantee the best quality. The public release of performance data in the form of quality and outcomes information about providers and hospitals forms part of this model [1]. It is essential to the success of the system that patients use this information in their decision-making processes. Websites like http://www.kiesbeter.nl or http://www.independer.nl were developed to enable patients to proactively select a hospital. It is assumed that with the information gleaned from these websites patients can 'vote' with their feet and choose only those healthcare providers that offer the best care [2]. A similar effect is attributed to the role of social media [3-5] although this role has not been confirmed by empirical research. Other research does not support this view [6]. That study suggests that policy makers should not count on demand-driven healthcare succeeding if it depends on active consumers consulting performance data and then acting upon that information to choose a hospital when in need of hospital services [1]. The failure of the demand-driven care model in hospital care might be related to several factors.

Firstly, not all relevant information is available in a centralized database. There are studies which indicate that $30 \%$ of consumers report that quality ratings are simply not available for the specific hospital they seek to assess [7].

Secondly, not all information about hospitals is understandable for patients and can be implemented in the healthcare choices that need to be made.

Thirdly, not all information is valued by patients. It is commonly believed that offering consumer choice makes them feel participatory, empowered, happier and more in control [8]. However reports that consumers become more stressed and disappointed when confronted with increasing degrees of choice.

Fourthly, not all information is trusted by patients. Consumers do not always trust performance data in general. Their distrust may be related both to the source of the information and to the data collection method.

If patients do not consider public information to be relevant to their hospital choice, then the question that arises is, what criteria do they have in mind when they choose a hospital? The literature suggests various variables.

Location is an important variable in determining the choice of either a physician or a hospital. Salisbury [9] found that with hospital choice distance was the most important factor for patients. Patients also prefer the hospital they have previous experience with to a hospital that might have higher quality rating [7].

Research has revealed that advice from family and friends is a preferred source of information for patients considering their hospital choice $[10,11]$.

*Corresponding author: Christiaan J. Lako, Department of public Administration Radboud University Nijmegen, Hk Nijmegen, P.o. Box 9108,6500, The Netherlands, E-mail: c.lako@fm.ru.nl

Received December 06, 2011; Accepted March 19, 2012; Published March 24 2012

Citation: Bartelink S, Lako CJ (2012) How do the Dutch Choose their Hospitals? Results from a Survey among 311 Patients. J Health Med Informat S6:002. doi:10.4172/2157-7420.S6-002

Copyright: (c) 2012 Bartelink S, et al. This is an open-access article distributed under the terms of the Creative Commons Attribution License, which permits unrestricted use, distribution, and reproduction in any medium, provided the original author and source are credited. 
But not everyone selects a hospital in the same way. Research has shown that people of different ages differ in the factors they take into account when choosing a hospital $[8,12]$. Made a distinction between two groups, maximizers and satisfiers, who have different standards and values. Motivaction [13] took this distinction between groups even further and made a model in which three different patient groups were distinguished. The three patient groups Motivaction [13] describes are: the less self-reliant, the pragmatic and the socially critical. They differ according to their values. The first group is not satisfied with their health, they demand a lot of care and the information about treatment should be easy to understand. These patients are inclined to depend heavily on their GP. Less self-reliant patients have been shown to be docile and to be somewhat passive in their health behavior. The pragmatic patients are very satisfied with their health, but they demand the best quality and are willing to pay for it. The socially critical patient group can be placed between the other two patient groups. All three patient groups have their own standards and values. Therefore it is possible that these patient groups will differ in the way they choose a hospital.

In addition, it has been shown that the advice of physicians, nurses or other medical personnel is more important for patients than performance card reports.

Finally, recent studies show that choices are not only determined by the information presented to patients, but also by their feelings about these choices and to a certain extent by what other people choose $[14,15]$.

This study is designed to establish which factors are related to hospital choice and to determine whether there is, indeed, a role for websites and social media.

\section{Methods}

\section{Questionnaire}

Patients with non-acute ailments visiting the hospital clinics within the departments of ENT, pediatrics, neurology, ophthalmology, orthopedics, surgery, gynecology and rehabilitation at the CWZ were invited to fill in a self-administered questionnaire about the process of hospital choice. They were asked: 'Why did you come to the CWZ hospital with your medical problems'? Patients indicating they were referred by their GP were asked how the referral was carried out. It could have been that they had left the choice to the GP; they could indicate that. However, it could also be indicated by the patients that their GP presented them with various alternatives and that they jointly chose the hospital. Patients could finally indicate that they had presented their choice to their GP.

Several factors were included in our study to explain why the patients went to that particular hospital. Patients were asked which factors were decisive. Answer categories included the advice from the physician, the information from national websites, information drawn from the hospital's website, information from Facebook and Twitter, the reputation of the hospital, the distance from the patient's house, possible previous experience with that hospital and their feelings about the hospital in question. Moreover, information about sociodemographic variables was included in the questionnaire, including age, gender and education level.

\section{Sample}

Apart from the CWZ hospital, there are several other hospitals in the Nijmegen area. In June 2011, a sample was drawn from patients who were seeking out-patient care from hospital-based clinics. It was a convenient sample with consecutive patients.

A total of 419 patients visiting the hospital was included. The response rate was $74 \%(n=311)$. The sample was fairly representative for Dutch population visits made to departments at Dutch hospitals in 2010 except for the age variable; the elderly were somewhat overrepresented.

\section{Data-analysis}

Data were analyzed with SPSS using bivariate analysis with $\chi^{2}$ Cramers $\mathrm{V}$ and multinomial regression analysis that is especially appropriate for the study of nominal variables.

\section{Results}

Only $1.3 \%$ of the patients reported having used public information to make their hospital choice. Less than two percent (1.7) suggested that Facebook and Twitter had been important when selecting a suitable hospital. It should be considered that $95 \%$ of the Dutch has access to the internet. They are supposed to be familiar with the internet [16].

More than $85 \%$ stated that they had been referred by their GP. Almost 29\% of those interviewees left the choice to the GP, $24 \%$ reported that the GP presented several options to them and 32\% had conversely presented their choice to the GP. It was found that younger people are less inclined to leave the hospital choice to their GP than older people $\left(\chi^{2}=15.4, \mathrm{df}=6\right.$, Cramer's $\left.\mathrm{V}=0.12, \mathrm{p} \leq 0.05\right)$. Table 1 shows that patients who consider previous experience with the hospital to be very important are less likely to leave the hospital choice to the GP than the remaining patients $\left(\chi^{2}=15.6, \mathrm{df}=6\right.$, Cramer's $\mathrm{V}=0.16$, $\mathrm{p} \leq 0.05$ ). It might be that the first group, unlike the latter, are more likely to make independent decisions, but our survey does not provide further information on this relationship.

The data presented in Table 2 suggest that patients who consider their feelings about the hospital to be very important are less likely to leave the hospital choice to the GP than were the other patients $\left(\chi^{2}=\right.$ $15.4, \mathrm{df}=6$, Cramer's $\mathrm{V}=0.16, \mathrm{p} \leq 0.05$ ). It might be that the first, as opposed to the latter, are more likely to decide alone. The survey cannot provide more detailed information on this aspect as it was not designed to study this relationship.

\begin{tabular}{|l|c|c|c|}
\hline \multicolumn{4}{|c|}{ Previous experiences with the hospital } \\
\hline Hospital choice & Not important & Neutral & Important \\
\hline Patient leaves choice to the GP & 37.1 & 30.3 & 28.8 \\
\hline GP presents several options to the patient & 27.8 & 9.1 & 25.4 \\
\hline Patient presents a choice to the GP & 16.9 & 45.5 & 37.0 \\
\hline Other & 15.5 & 15.2 & 13.8 \\
\hline Total & 100.0 & 100.0 & 100.0 \\
\hline
\end{tabular}

Table 1: Patient hospital choice according to the importance attached to previous experiences with the hospital in question (in percent; $n=311$ ).

\begin{tabular}{|l|c|c|c|}
\hline \multicolumn{4}{|c|}{ Feelings about the hospital } \\
\hline Hospital choice & Not important & Neutral & Important \\
\hline Patient leaves choice to the GP & 36.6 & 34.9 & 16.2 \\
\hline GP presents several options to the patient & 21.4 & 20.6 & 29.9 \\
\hline Patient presents a choice to the GP & 29.8 & 33.3 & 35.0 \\
\hline Other & 12.4 & 11.1 & 18.8 \\
\hline Total & 100.0 & 100.0 & 100.0 \\
\hline
\end{tabular}

Table 2: Patient hospital choice according to the importance attached to feelings about the hospital (in percent; $n=311$ ). 


\begin{tabular}{|l|c|c|c|}
\hline \multicolumn{4}{|c|}{ Patient group } \\
\hline Hospital choice & Less self-relian & Critical & Pragmatic \\
\hline Patient leaves choice to the GP & 35.1 & 27.5 & 20.5 \\
\hline GP presents several options to the patient & 20.1 & 25.0 & 29.9 \\
\hline Patient presents a choice to the GP & 35.1 & 32.5 & 29.1 \\
\hline Other & 9.7 & 15.0 & 20.5 \\
\hline Total & 100.0 & 100.0 & 100.0 \\
\hline
\end{tabular}

Table 3: Patient hospital choice according to patient group (in percent; $n=311$ ).

\begin{tabular}{|l|c|c|c|}
\hline \multicolumn{4}{|c|}{ Opinion of the GP about the hospital } \\
\hline Hospital choice & $\begin{array}{c}\text { Not im- } \\
\text { portant }\end{array}$ & $\begin{array}{c}\text { Somewhat } \\
\text { important }\end{array}$ & $\begin{array}{c}\text { Very } \\
\text { important }\end{array}$ \\
\hline Patient leaves choice to the GP & 9.7 & 21.2 & 37.7 \\
\hline GP presents several options to the patient & 8.1 & 16.7 & 32.8 \\
\hline Patient presents a choice to the GP & 45.2 & 45.5 & 23.5 \\
\hline Other & 37.1 & 16.7 & 6 \\
\hline Total & 100.0 & 100.0 & 100.0 \\
\hline
\end{tabular}

Table 4: Patient hospital choice according to the importance attached to the opinion of the GP about the hospital in question (in percent; $n=311$ ).

\begin{tabular}{|l|c|c|c|c|}
\hline \multicolumn{4}{|c|}{ Model } & \\
\hline & $\begin{array}{c}-2 \text { log likelihood of } \\
\text { reduced model }\end{array}$ & $X^{2}$ & Df & Signif. \\
\hline Variable Opinion of the GP & 546.889 & 70.478 & 3 & 0.000 \\
\hline Age & 489.115 & 12.704 & 3 & 0.005 \\
\hline Previous experiences & 487.946 & 11.535 & 3 & 0.009 \\
\hline Patient group & 486.863 & 10.452 & 3 & 0.015 \\
\hline
\end{tabular}

Table 5: Final model regression analysis.

Table 3 reveals that patients who view themselves as less self-reliant are more likely to leave hospital choice to the GP than are other patients $\left(\chi^{2}=13.6, d f=6\right.$, Cramer's $\left.V=0.15, p \leq 0.05\right)$. Data presented in Table 4 suggest that patients who consider the opinion of the GP to be very important are more likely to leave the hospital choice to the GP than the remaining patients $\left(\chi^{2}=70.2, \mathrm{df}=6\right.$, Cramer's $\left.\mathrm{V}=0.34, \mathrm{p} \leq 0.05\right)$.

Table 5 presents the outcomes of the multinomial regression analysis. It suggests that four variables explain the differences in hospital choice. The opinion of the GP about the hospital is the most important factor. Belonging to a specific patient group is the least important aspect. The model explains $33 \%$ of the variance.

\section{Conclusion}

This study shows that hospital choice is a decision-making process that relies more heavily on personal information from the GP than on websites or social media. The admitting physician is still the most important factor. This outcome corroborates results from earlier studies $[1,17]$.

The role of websites and social media, including Facebook and Twitter, could not be clearly established in this study which does not rule out the possibility that social media may become much more important in the near future. At present, Dutch hospitals seem to use social media to distribute information to patients, but they do not seem to use it to give patients the opportunity to respond or engage. It might be better to change the unidirectional nature of hospital communication. In turn, that would stimulate the use of social media in patient hospital choice. On the basis of our study, we reject the assumption that patients in the Netherlands are rational consumers using public information from websites or social media in their hospital choice. It might be that physicians and peers are preferred sources of information because public information from websites or social media seems impersonal.

Every empirical study involves limitations as does this study. Caution with respect to results is usually warranted. Some caution with our results is needed. Younger people, who generally use more social media, were underrepresented in this study. This means that the role of the social media among the general population visiting departments of Dutch hospitals might be slightly greater than indicated in this study though still insignificant. The risk of social desirability has been reduced by the utilization of self-administered questionnaires. In person, one-to-one interviews with patients would have probably resulted in more social desirability effects. During such interviews the opportunities for patients to clarify their use of social media might have been greater. The hospital studied, The CWZ hospital, is one out of two hospitals in this area. Had our study undertaken in another region, for example Rotterdam, where there is more competition for patients, the results might have been different. However, there is no reason, a priori, to believe this is the case [1]

\section{Acknowledgements}

The clinicians and the nurses of the departments of the hospital are kindly acknowledged for their contribution to the collection of the data. The authors kindly acknowledge Thomas Klijn of the CWZ hospital for his role in the collection of the data.

\section{References}

1. Lako CJ, Rosenau P (2009) Demand-Driven Care and Hospital Choice. Dutch Health Policy Toward Demand-Driven Care: Results from a Survey into Hospital Choice. Health Care Anal 17: 20-35

2. (2003) Public reporting of health quality information. Health Aff 22: 72

3. Gillen $P$ (2007) The New Influencers: A Marketer's Guide to the New Socia Media. Quill Driver Books Sanger, CA.

4. Thaker SI, Nowacki AS, Metha NB, Edwards AR (2011) How U.S. Hospitals Use Social Media. Ann Intern Med 154:707-708.

5. Sarringhaus M (2011) The great divide: social media's role in bridging healthcare's generational shift. J Healthc Manag 56: 235-244.

6. Meijer A (2004) Vreemde ogen dwingen. De betekenis van internet voor maatschappelijke controle in de publieke sector: Den Haag

7. Kaiser Family Foundation, Agency for Healthcare Research and Quality \& Harvard School of Public Health. (2004). National Survey on Consumers' Experiences with Patient Safety and Quality Information: Kaiser Family Foundation.

8. Schwartz B (2004) The paradox of choice. Why More Is Less: Harper Collins.

9. Salisbury CJ (1989) How do people choose their doctor? BMJ 299: 608-610.

10. Edgman-Levitan S, Cleary P (1996) What information do consumers want and need? Health Aff 15: 42-56.

11. Isaacs SL (1996) Consumer's information needs: results of a national survey. Health Aff 15: 31-41.

12. Reijnders W, De Jonge $L$ (2007) Keuzeprocessen in de gezondheidszorg. De hefboom voor verandering is de kiezende zorgconsument. ZM Magazine 2: 15-18.

13. Motivaction (2009) Wat werkt bij wie? Utrecht.

14. Tiemeijer WL (2011) Hoe mensen keuzes maken. De psychologie van he beslissen Amsterdam University Press.

15. Thaler RH, Sunstein, CR (2009) Nudge. Improving Decisions About Health Wealth, and Happiness: Yale University Press, New Haven, CT.

16. CBS (2011)

17. Burns LR, Woley DR (1992) The impact of physician characteristics in hospita choice; models for hospital care. J Health Econ 11: 43-62. 